\title{
Success after failure: the role of endometrial stem cells in recurrent miscarriage
}

\author{
Emma S Lucas ${ }^{1,2}$, Nigel P Dyer ${ }^{3}$, Katherine Fishwick ${ }^{1}$, Sascha Ott ${ }^{2,3}$ and Jan J Brosens ${ }^{1,2}$ \\ ${ }^{1}$ Division of Biomedical Sciences, Warwick Medical School, Coventry, UK, ${ }^{2}$ Tommy's National Centre for \\ Miscarriage Research, University Hospitals Coventry and Warwickshire NHS Trust, Coventry, UK and \\ ${ }^{3}$ Warwick Systems Biology Centre, University of Warwick, Coventry, UK
}

Correspondence should be addressed to J Brosens; Email: J.J.Brosens@warwick.ac.uk

\begin{abstract}
Endometrial stem-like cells, including mesenchymal stem cells (MSCs) and epithelial progenitor cells, are essential for cyclic regeneration of the endometrium following menstrual shedding. Emerging evidence indicates that endometrial MSCs (eMSCs) constitute a dynamic population of cells that enables the endometrium to adapt in response to a failed pregnancy. Recurrent miscarriage is associated with relative depletion of endometrial eMSCs, which not only curtails the intrinsic ability of the endometrium to adapt to reproductive failure but also compromises endometrial decidualization, an obligatory transformation process for embryo implantation. These novel findings should pave the way for more effective screening of women at risk of pregnancy failure before conception.

Reproduction (2016) 152 R159-R166
\end{abstract}

\section{Introduction}

Successful implantation of a human embryo is commonly attributed to binary variables; i.e. nidation of a 'normal', but not an 'abnormal', embryo in a 'receptive', but not a 'non-receptive', endometrium is required for a successful pregnancy. However, this implantation paradigm is based on animal studies, more specifically the mouse model (Wang \& Dey 2006). Like many other rodents, mouse reproductive success is based on quantity and is characterized by rapid breeding cycles, multiple synchronous implantations, large litter size and, crucially, huge natural selection among offspring (Taylor 2016). Mouse offspring "quality" is arrived at mainly through sibling rivalry after birth. By contrast, human pregnancy requires prolonged investment in a single foetus at considerable cost to the mother (Haig 1993). Maternal cost, and the risk of neonatal death, increases sharply with each additional foetus (e.g. twins, triplets etc.) (Refuerzo 2012). From an evolutionary perspective, a reproductive strategy based on prolonged maternal investment in singleton pregnancies makes sense only if based on an intrinsically dynamic and adaptable implantation process (Macklon \& Brosens 2014).

And it is. Cleavage-stage human embryos tolerate and actively generate aneuploid blastomeres through mitotic non-disjunction. As a consequence, most human embryos are mosaic (Vanneste et al. 2009, Taylor et al. 2014). With over 2500 distinct genetic errors documented to date (Fragouli et al. 2013), each implanting blastocyst is arguably unique. Furthermore, transient aneuploidy during development may not be unequivocally as 'bad' as has been intuitively presumed because of the obvious link with cancer and congenital abnormalities. Emerging evidence suggests that aneuploidy drives rapid phenotypic adaptation (Kaya et al. 2015, Liu et al. 2015, Millet et al. 2015), confers resistance to cellular stress (Chen et al. 2012, Duncan et al. 2012, Kaya et al. 2015) and arguably imparts invasiveness on embryos necessary for implantation and deep placentation. Recent reports demonstrated unequivocally that embryos harbouring complex mosaic aneuploidies can give rise to healthy offspring, both in humans and, experimentally, in mice (Greco et al. 2015, Bolton et al. 2016).

Several mechanisms ensure survival of mosaic embryos, including self-correction through apoptosis and possibly sequestration of aneuploid cells into the trophoblast lineage (Bolton et al. 2016) (Fig. 1). However, invasiveness combined with the exceptional diversity of human embryos necessitates the need for additional, external (i.e. uterine) selection to limit the risk of maternal investment in a failing pregnancy (Gellersen \& Brosens 2014, Macklon \& Brosens 2014). The first evidence that the endometrium is an intrinsic biosensor of embryo quality actually originated from studies in cattle. Microarray studies showed that the pregnant bovine 


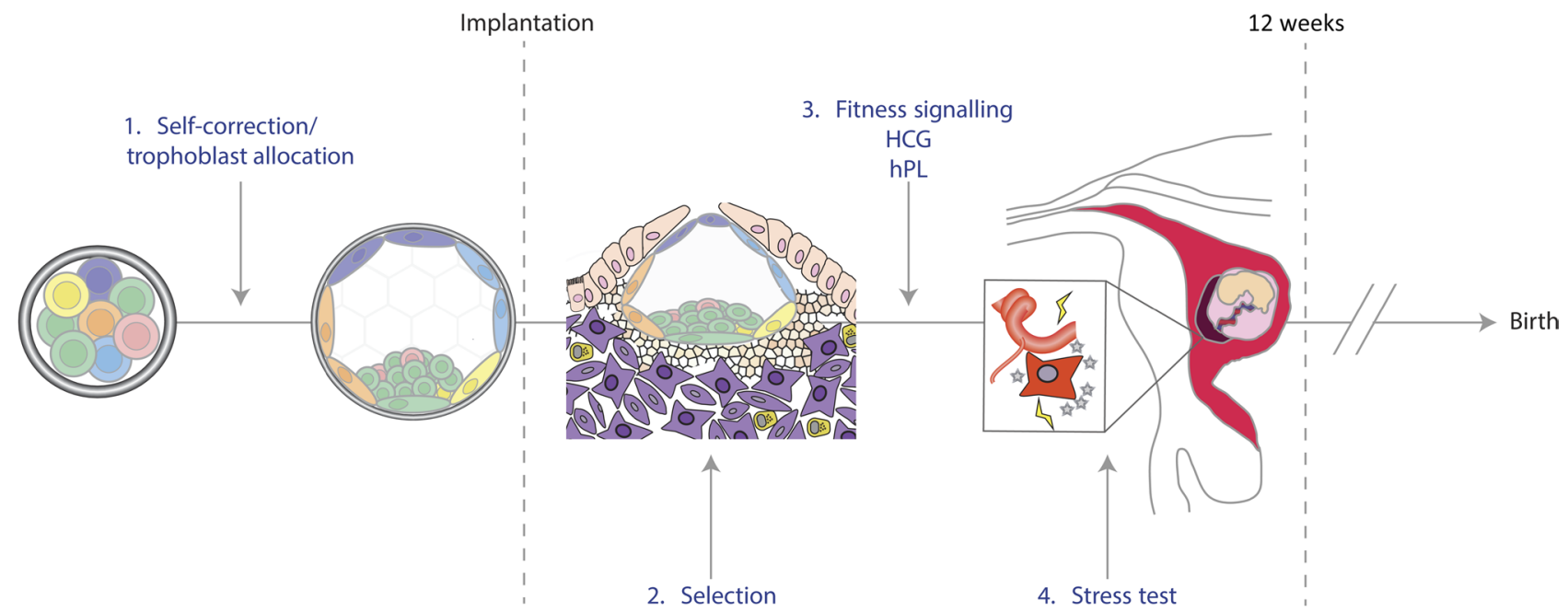

Figure 1 Embryo selection at implantation and recurrent miscarriage. Pre-implantation human embryos are remarkably diverse. Most human embryos are mosaic. Normal blastomeres are indicated in green whereas a different colour indicates a distinct aneuploidy. While embryonic mosaicism bestows adaptability onto the species through genetic diversity, it also increases the risk of prolonged maternal investment in a failing pregnancy. Several embryo-intrinsic and -extrinsic mechanisms operate in early pregnancy to limit this risk, including embryonic self-correction (1), biosensoring of embryo quality by decidualizing (purple) cells (2), corpus luteum rescue by placental fitness hormones such as hCG (3), and oxidative stress associated with the onset of placental perfusion at the end of the 1st trimester of pregnancy, effectively stress-testing the placental-decidual interface (4). Lack of embryo selection at implantation inevitably increases the risk of clinical miscarriage. Conversely, as a pregnancy transits to the 2 nd trimester, selection pressure decreases and the risk of further miscarriage drops markedly.

endometrium mounts a transcriptional response that is distinct for embryos generated by artificial insemination, IVF, or somatic cell nuclear transfer (Mansouri-Attia et al. 2009). Decidualizing human endometrial stromal cells have since emerged as exquisite sensors that respond to as yet unidentified embryonic serine proteases in a manner that either supports further development (positive selection) or ensures rapid disposal through menstruation-like shedding (negative selection) (Brosens et al. 2014). Quality control may not necessarily cease once the conceptus is embedded in the endometrium, but likely continues throughout the first trimester of pregnancy. For example, the gradual shift from ovarian to placental progesterone production arguably means that the endometrium will de facto select against embryos that are perceived to lack fitness because of insufficient human chorionic gonadotrophin production. Similarly, the onset of placental perfusion around week 10 of pregnancy causes dramatic changes in local oxygen tension and triggers bursts of free radicals (Burton et al. 1999) (Fig. 1), effectively stress-testing the foeto-maternal interface. Thus, suboptimal selection at implantation inevitably increases the risk of clinical miscarriage; and conversely, once all selection pressures have been endured successfully by the end of the 1st trimester, the likelihood of further catastrophic failure drops markedly (Fig. 1). The corollary of inefficient embryo selection at implantation is rapid conception, defined by short time-to pregnancy interval. It has been estimated that $40 \%$ of recurrent miscarriage patients are superfertile, defined by the fact that each pregnancy is achieved within three cycles (Salker et al. 2010, Teklenburg et al. 2010, Orlando \& Coulam 2014).

Endometrial stem cells are perhaps the least appreciated and least understood drivers of reproductive plasticity. Considering the unrivalled regenerative capacity of the endometrium, it is remarkable, if not baffling, that the first experimental study demonstrating the presence of resident endometrial mesenchymal stem cells (eMSCs) was reported only 12 years ago (Chan et al. 2004). eMSCs are abundant, multipotent, immunoprivileged and highly regenerative in various pre-clinical models of disease (reviewed in Mutlu et al. 2015).

In this commentary, we explore the role of endometrial MSCs in effecting one of the most salient aspects of human reproduction, i.e. the ability to achieve a live birth after multiple pregnancy failures.

\section{Persistent reproductive failure}

One of the most disappointing aspects of modern reproductive medicine is the pervasive puerile view of implantation and early pregnancy. Patients suffering from reproductive failure, i.e. repeated IVF implantation failures or recurrent miscarriage, continue to be subjected to a battery of screening tests for subclinical 'disorders', which are presumed to converge somehow onto a 'fragile' implanting embryo, causing reproductive failure. Numerous anatomical, endocrine, immunological, thrombophilic and genetic perturbations have been invoked to explain persistent reproductive failure (Rai \& Regan 2006, Agenor \& Bhattacharya 2015). 
Yet every diagnostic test currently in clinical practice lacks specificity, meaning that many women with normal pregnancies also test positive. Nevertheless, it remains standard practice to label a 'positive' test as 'causal', ignoring the lack of clinical evidence, biological plausibility or the absence of interventions that are even remotely effective. In the absence of a 'positive' test, many clinicians resort to exalting the virtues of vitamins, micronutrients and other soft interventions. Others advocate an interventional approach, using a range of combinatory empirical treatments (e.g. heparin, aspirin, steroids, human chorionic gonadotrophin, intravenous immunoglobulin, hydroxychloroquine, intralipids, TNF $\alpha$ inhibitors etc.) as well as pre-implantation genetic screening of IVF embryos. None of these interventions have been conclusively shown to improve reproductive success; and some may well be harmful.

Yet, despite this lamentable state of affairs, most women suffering either repeated implantation failure or recurrent miscarriage do achieve a successful pregnancy (Brigham et al. 1999, Ogasawara et al. 2000, Practice Committee of the American Society for Reproductive Medicine 2012, Saravelos \& Regan 2014, Vlaanderen 2014), irrespective of treatment. For example, several randomized control trials on recurrent miscarriage, defined here as three consecutive pregnancy losses, reported life births rate of $65 \%$ or more in the placebo group (Coomarasamy et al. 2015, Pasquier et al. 2015). In recurrent miscarriage, the incidence of euploid foetal loss increases with each additional miscarriage, whereas the likelihood of a future successful pregnancy gradually decreases (Ogasawara et al. 2000). These observations indicate that RM is a graded disorder with the level of severity defined by the number of previous pregnancy losses. Nevertheless, even after five consecutive miscarriages, the likelihood of a life birth in the subsequent pregnancy remains in excess of $50 \%$ (Brigham et al. 1999, Rai \& Regan 2006).

A parsimonious explanation for these clinical observations is that embryo-endometrial interactions are intrinsically dynamic and capable of adapting from pregnancy to pregnancy to ensure reproductive success. However, the more severe the defect, the higher the likelihood of repeated pregnancy failures in consecutive conception cycles.

\section{The decidualizing endometrium in recurrent miscarriage}

Much of the work on the endometrium in the context of recurrent miscarriage has focused on decidualization, an obligatory transformative process for pregnancy in all mammalian species where implantation involves breaching of the luminal endometrial epithelium by the conceptus (Ramsey et al. 1976). The decidual process is foremost characterized by transformation of endometrial fibroblasts into specialized epithelioid cells. In parallel, the endometrium undergoes extensive remodelling, effected by the influx of specialized immune cells, predominantly uterine natural killer cells and macrophages (reviewed by Gellersen and Brosens 2014). Associated vascular changes then prepare the human endometrium for endovascular trophoblast invasion and the formation of a functional haemochorial placenta (Brosens et al. 2002). Decidual cells encapsulate and safeguard the conceptus against various stressors. For example, stress-induced signalling through c-Jun $\mathrm{N}$-terminal kinase and p38 mitogenactivated protein kinase pathways is selectively inactivated upon decidualization of human endometrial stromal cells (Yoshino et al. 2003, Leitao et al. 2010, 2011). In parallel with a marked induction of various free radical scavengers, silencing of stress-signalling pathways renders decidual cells extraordinarily resistant to oxidative cell death (Kajihara et al. 2006). Moreover, circadian oscillations within the endometrium are firmly disabled upon decidualization (Muter et al. 2015), which further isolates the implanting blastocyst from the maternal environment. Decidual cells are also gatekeepers and chief modulators of local immune cells at the embryo-endometrial interface. In pregnancy, decidual cells also actively prevent influx of antigenspecific cytotoxic T lymphocytes by silencing of genes encoding key chemokines (Nancy et al. 2012).

Importantly, decidualization is not an all-ornothing phenomenon. Instead, differentiating human endometrial stromal cells transit through distinct functional phenotypes upon transformation into decidual cells (Salker et al. 2012, Lucas et al. 2016). This transitional pathway, which can be recapitulated in culture, is characterized initially by an acute proinflammatory response, lasting several days. Release by differentiating endometrial stromal cells of 'alarmins' like interleukin-33, a potent activator of the innate immune system, has emerged as an important driver of this transient inflammatory process (Salker et al. 2012). These inflammatory mediators in turn up-regulate the expression of key implantation genes, including leukaemia inhibitory factor, interleukin $1-\beta$, heparin binding EGF, bone morphogenetic protein 2, winglessrelated MMTV integration site 4, and homeobox protein 10. Acquisition of a mature decidual phenotype curtails the inflammatory response through induction of antiinflammatory soluble decoy receptors (Salker et al. 2012) and pronounced up-regulation of $11 \beta$-hydroxysteroid dehydrogenase type 1, leading to increased local cortisol production (Kuroda et al. 2013a,b). Decidual factors such as LEFTY2 contribute to the active closure of the window of receptivity (Tabibzadeh et al. 2000, Tang et al. 2005). As aforementioned, mature decidual cells are exquisitely responsive to embryo signals, especially trypsin-like proteases, and engage in active rejection by triggering menstruation-like shedding mediated by a decidual stress response (Brosens et al. 2014). 
Taken together, these observations illustrate how the decidualization pathway contributes to the functional transition of the endometrium from a nonreceptive (early-secretory phase) to a receptive (mid-secretory phase) and then a selective (late-secretory phase) state.

The hallmark of the endometrium in recurrent miscarriage is a disordered and prolonged proinflammatory decidual response. This excessive inflammatory response in turn prolongs the 'window of receptivity', promotes out-of-phase implantation, and disables embryo selection (Salker et al. 2010, 2011, 2012, Lucas et al. 2016). Consequently, poor-quality embryos are not disposed of in a timely manner and high-quality embryos implant in an unsupportive environment. Both scenarios lead to clinical miscarriage.

\section{'Memory' of endometrial stromal cells}

A truly prodigious finding, reported first 10 years ago, is that human endometrial stromal cells from individual patients closely phenocopy the decidual response in vivo upon differentiation in culture (Klemmt et al. 2006). Aberrant decidualization in culture has not only been reported for recurrent miscarriage patients (Francis et al. 2006, Salker et al. 2010) but also for endometriosis (Klemmt et al. 2006, Aghajanova et al. 2011, Ahn et al. 2016) and polycystic ovary syndrome (Piltonen et al. 2013, Piltonen et al. 2015). However, while progesterone resistance, defined by the refractoriness of cultured human endometrial stromal cells to deciduogenic cues (Barragan et al. 2016), characterizes endometriosis patients; an excessive and prolonged inflammatory decidual response is typically associated with recurrent miscarriage (Salker et al. 2012).

We hypothesized that an epigenetic mechanism may underlie this pathological 'memory' of endometrial stromal cells associated with recurrent miscarriage. Consequently, we sequenced immunoprecipitated methylated DNA (MeDIP-seq) to compare the global cytosine methylation profiles in primary cultures established from mid-luteal biopsies from recurrent miscarriage patients and control subjects (Lucas et al. 2016). Disappointingly, the methylation signature at CG dinucleotides, the most common context of DNA methylation, was largely similar between the clinical groups, although there were notable differences in genes associated with decidualization and implantation processes, including the progesterone receptor co-activator high-mobility group box 2 (HMGB2) (Boonyaratanakornkit et al. 1998).

Some MeDIP-seq analysis pipelines utilize protocols based on the assumption that methylation is confined to CpG dinucleotides. When we re-analysed the sequencing data using an unrestricted approach, a striking signature became apparent in endometrial stromal cells isolated from recurrent miscarriage samples, characterized by hypomethylation of 2741 loci. These differentially methylated regions (DMRs) overwhelmingly mapped to CA-rich regions that were largely devoid of CpG dinucleotides. Many DMRs not only clustered within $15 \mathrm{Mb}$ of the telomeres but also contained several DNA motifs that were selectively hypomethylated in recurrent miscarriage patients (Lucas et al. 2016).

Methylation at $\mathrm{CpH}(\mathrm{H}=\mathrm{A}, \mathrm{C}, \mathrm{T})$ is an epigenetic hallmark of stem cells, embryos and gametes (Ramsahoye et al. 2000, Shirane et al. 2013). It is lost in most somatic tissues but can be re-established upon pluripotency reprogramming of somatic cells (Ziller et al. 2011). Hence, we reasoned that the global $\mathrm{CpH}$ hypomethylation signature in endometrial stromal cells from recurrent miscarriage patients could be accounted for by lack of eMSCs or stemness.

\section{eMSCs in recurrent miscarriage}

The defining feature of the human sexual cycle, shared with few other mammals, is menstruation. This remarkable phenomenon is triggered by falling progesterone levels in species that exhibit cyclic decidualization of the endometrium independently of an implanting embryo. MSCs regulate the main phases of wound healing via modulation of inflammatory response, promotion of angiogenesis and stimulation of cell movement (reviewed by Wong et al. 2015, Wang et al. 2016); thus, a role for these cells in endometrial regeneration following menstruation, miscarriage or parturition is obvious. Endometrial MSCs share the classic properties of bone marrow MSCs, including clonogenicity, multipotency, the ability to reconstitute endometrial stroma in vivo and expression of surface markers that distinguish them from leucocytes, haematopoietic and endothelial cells (reviewed by Gargett et al. 2016).

As described for other organs, eMSCs predominantly reside in the perivascular niche of both the basal and functional layers (Masuda et al. 2012, Ulrich et al. 2014). Screening the endometrium with a panel of perivascular markers identified SUSD2 (W5C5) as a powerful marker for selection of clonogenic endometrial cells (Masuda et al. 2012). The SUSD2/ W5C5-positive cell population isolated by magnetic activated cell sorting constitutes approximately $6-7 \%$ of endometrial stromal cells. The SUSD2/W5C5-positive cell fraction contains on average $2-4 \%$ clonogenic cells (Masuda et al. 2012, Murakami et al. 2013). However, clonogenic eMSCs can also be isolated from the SUSD2/W5C5-negative cell fraction, although the relative abundance is much lower $(0.7 \%)$ (Murakami et al. 2013). A recent gene expression profiling study provided compelling evidence that clonogenic eMSCs residing in the perivascular niche are the lineage precursors of the more committed non-perivascular eMSCs (Barragan et al. 2016). 
To explain the $\mathrm{CpH}$ hypomethylation signature in endometrial stromal cells of recurrent miscarriage patients, we systematically measured the total number of freshly isolated SUSD2/W5C5-positive cells, the abundance of clonogenic SUSD2/W5C5-positive eMSCs and the abundance of clonogenic SUSD2/ W5C5-negative eMSCs in mid-luteal biopsies obtained from 31 recurrent miscarriage patients and 28 control subjects. The total number of SUSD2/W5C5-positive cells did not differ between the study and control groups. However, recurrent miscarriage was associated with a $41 \%$ reduction in the abundance of clonogenic SUSD2/W5C5-positive eMSCs, respectively. Strikingly, no clonogenic SUSD2M5C5-negative eMSCs were recovered from 13 out of $31(42 \%)$ recurrent miscarriage samples compared with 3 out of $28(11 \%)$ control samples (Lucas et al. 2016).

Both the level of methylation and the abundance of clonogenic cells correlated inversely with the severity of the miscarriage phenotype, defined by the number of previous pregnancy losses. Furthermore, eMSC deficiency has profound ramifications downstream of the differentiation pathway by accumulating senescent cells in the endometrial stromal compartment. Cellular senescence is associated with distinct pro-inflammatory cytokines and chemokines, matrix metalloproteinases and growth factors, termed senescence-associated secretory phenotype (SASP) (Acosta et al. 2013). Importantly, induction of senescence in primary endometrial stromal cells triggered a blunted but prolonged inflammatory secretory response upon decidualization, akin to the secretory response of primary cultures from recurrent miscarriage patients and likely reflecting the contribution of SASP (Lucas et al. 2016).

\section{Perspective}

The advances in endometrial stem cell biology have generated innovative tools to accurately quantify and characterize eMSC populations associated with reproductive failure. Importantly, these advances are also rewriting our understanding of the biology of endometrial stromal cells. Rather than being a homogenous population, endometrial stromal cells, in vivo and in vitro, consist of a community of cells, ranging from quiescent and active MSCs, transit-amplifying cells, mature fibroblasts and senescent cells. The observation that relative MSC deficiency and heightened cellular senescence is associated with recurrent miscarriage exemplifies that the decidual response, or more precisely the transitional decidual pathway, is determined by the balance of subpopulations that make up the community of stromal cells (Fig. 2). By default, the constituents of this community, and thus the nature of the decidual response, changes with increasing distance away of the perivascular niche. A recent study illustrated this spatial organization in the endometrium by demonstrating that perivascular SUSD2/W5C5-positive cells mount a distinct decidual response that could account for preferential homing of invading trophoblast to the spiral arteries (Murakami et al. 2014).

What causes eMSC deficiency in the uterus is a pertinent but as yet unanswered question. The properties and potential of adult stem cells are determined by a
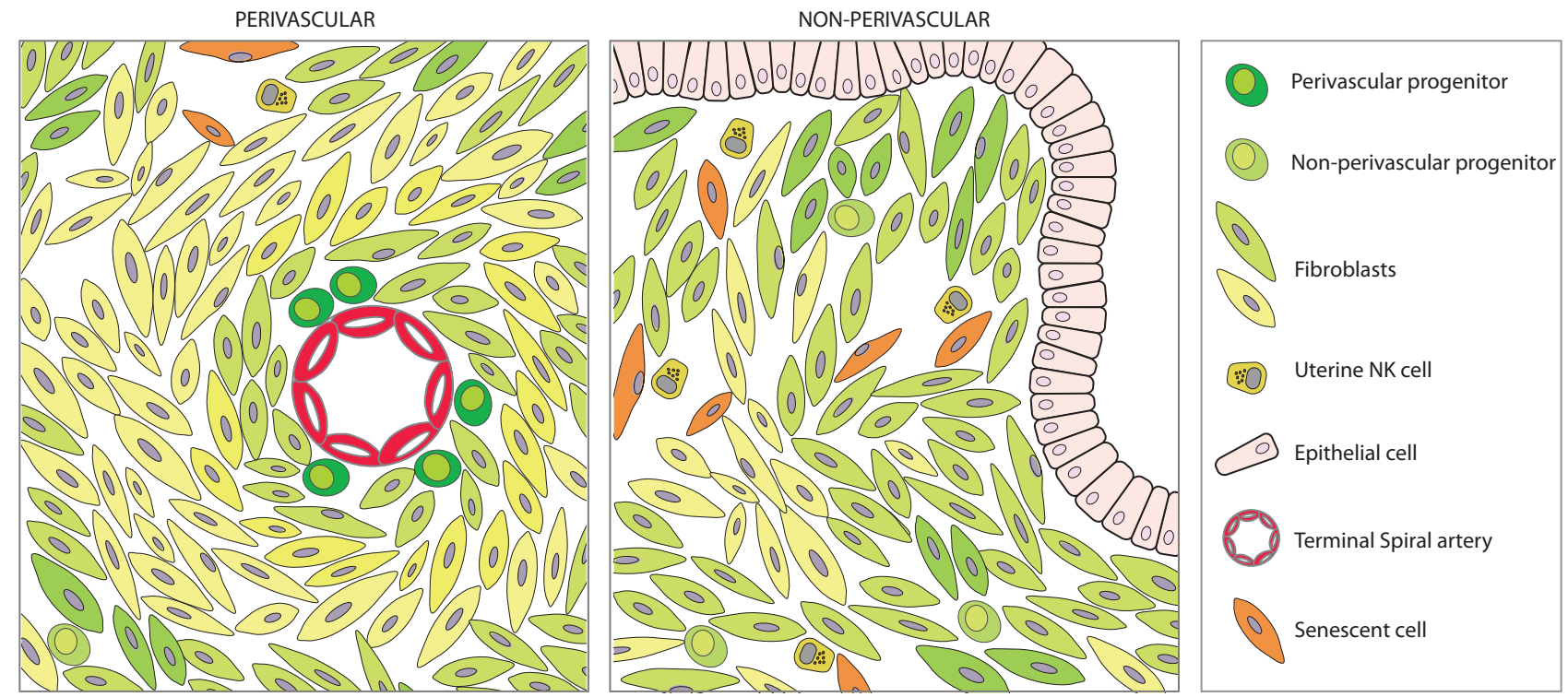

Figure 2 Endometrial stromal compartment: a 'community' affair. The stromal compartment of the endometrium is a mixed community of cells of quiescent and active MSCs, transit-amplifying cells, mature fibroblasts and senescent cells. The composition of this community changes with increased distance from the perivascular niche. The effect of eMSC deficiency is amplified downstream of the perivascular niche. Failure of homeostatic balancing of the constituents of the stromal community accounts for aberrant decidualization associated with recurrent miscarriage. 
combination of intrinsic characteristics and a tissuespecific microenvironment. High Notch activity is a common niche feature and essential for cell-fate specification and maintenance of stem cells in a poised quiescent state (Bjornson et al. 2012, Cheung \& Rando 2013). For example, silencing of Notch signalling in skeletal cells leads to stem cell depletion and gives rise to muscles that lack the ability to regenerate in response to injury (Bjornson et al. 2012). By analogy, it seems plausible that pathological cues arising from dysmetabolic conditions associated with adverse pregnancy outcome, such as obesity, interfere with Notch signalling in the endometrium, thus gradually depleting the tissue of quiescent stem cells and rendering it vulnerable to damage in pregnancy. In support of this conjecture, a previous study reported that body mass index negatively correlates with cloning efficiency of endometrial SUSD2/W5C5-positive and -negative eMSCs (Murakami et al. 2013). Age, on the other hand, has no or little impact on the abundance of eMSCs (Murakami et al. 2013, Ulrich et al. 2014).

These observations lead to other pertinent questions. How does the endometrium maintain its MSC populations over 400 or so cycles of tissue breakdown and regeneration? Is expansion of the eMSC population required to accommodate pregnancy? A widely held assumption is that eMSCs residing in the basal layer, which is not shed during menstruation, maintain the regenerative capacity of the endometrium from menarche until the menopause and beyond. However, this seems unlikely as age does not seem to impact on the abundance of eMSCs. An alternative scenario is that influx of immune cells, and specifically uterine natural killer cells, during the luteal phase plays a key role in homeostatic balancing of the stromal subpopulations through selective clearance of senescent cells (Hoenicke \& Zender 2012). This attractive but as yet unproven scenario would link aberrant immune cell function to subsequent pregnancy failure without having to invoke a host-versus-graft response to the invading placental semi-allograft. Finally, it is not beyond the realms of possibility that decidual or trophoblast cues lead to expansion of eMSC population, in parallel with the expansion of the vascular bed. If this is the case, it would explain how the endometrium could self-correct over time and enable recurrent miscarriage patients to achieve a successful pregnancy after consecutive previous failures.

In summary, the discovery that eMSC deficiency is linked to recurrent miscarriage has provided new insights into the mechanisms of aberrant decidualization, lack of embryo selection and pregnancy failure. At the same time, new questions have arisen regarding the mechanisms that control the maintenance of eMSCs from cycle to cycle and from pregnancy to pregnancy. Screening for eMSC deficiency may identify women at risk of recurrent reproductive failure and, conversely, harnessing the mechanisms that control endometrial stem cell populations may lead to effective interventions that reduce the physical and emotional trauma caused by recurrent miscarriage.

\section{Declaration of interest}

The authors declare that there is no conflict of interest that could be perceived as prejudicing the impartiality of the review reported.

\section{Funding}

This work was supported by the Biomedical Research Unit in Reproductive Health, a joint initiative between University Hospitals Coventry and Warwickshire NHS Trust and Warwick Medical School. E S L and J J B are currently funded by Tommy's National Miscarriage Research Centre.

\section{References}

Acosta JC, Banito A, Wuestefeld T, Georgilis A, Janich P, Morton JP, Athineos D, Kang TW, Lasitschka F, Andrulis M et al. 2013 A complex secretory program orchestrated by the inflammasome controls paracrine senescence. Nature Cell Biology 15 978-990. (doi:10.1038/ncb2784)

Agenor A \& Bhattacharya S 2015 Infertility and miscarriage: common pathways in manifestation and management. Womens Health 11 527-541. (doi:10.2217/whe.15.19)

Aghajanova L, Tatsumi K, Horcajadas JA, Zamah AM, Esteban FJ, Herndon CN, Conti M \& Giudice LC 2011 Unique transcriptome, pathways, and networks in the human endometrial fibroblast response to progesterone in endometriosis. Biology of Reproduction 84 801-815. (doi:10.1095/biolreprod.110.086181)

Ahn JI, Yoo JY, Kim TH, Kim YI, Ferguson SD, Fazleabas AT, Young SL, Lessey BA, Ahn JY, Lim JM et al. 2016 cAMP-response elementbinding 3-like protein 1 (CREB3L1) is required for decidualization and its expression is decreased in women with endometriosis. Current Molecular Medicine 16 276-287. (doi:10.2174/156652401666616022 5153659)

Barragan F, Irwin JC, Balayan S, Erikson DW, Chen JC, Houshdaran S, Piltonen TT, Spitzer TL, George A, Rabban JT et al. 2016 Human endometrial fibroblasts derived from mesenchymal progenitors inherit progesterone resistance and acquire an inflammatory phenotype in the endometrial niche in endometriosis. Biology of Reproduction 94118. (doi:10.1095/biolreprod.115.136010)

Bjornson CR, Cheung TH, Liu L, Tripathi PV, Steeper KM \& Rando TA 2012 Notch signaling is necessary to maintain quiescence in adult muscle stem cells. Stem Cells 30 232-242. (doi:10.1002/stem.773)

Bolton H, Graham SJ, Van Der Aa N, Kumar P, Theunis K, Fernandez Gallardo E, Voet T \& Zernicka-Goetz M 2016 Mouse model of chromosome mosaicism reveals lineage-specific depletion of aneuploid cells and normal developmental potential. Nature Communications 7 11165. (doi:10.1038/ncomms11165)

Boonyaratanakornkit V, Melvin V, Prendergast P, Altmann M, Ronfani L, Bianchi ME, Taraseviciene L, Nordeen SK, Allegretto EA \& Edwards DP 1998 High-mobility group chromatin proteins 1 and 2 functionally interact with steroid hormone receptors to enhance their DNA binding in vitro and transcriptional activity in mammalian cells. Molecular and Cellular Biology 18 4471-4487. (doi:10.1128/MCB.18.8.4471)

Brigham SA, Conlon C \& Farquharson RG 1999 A longitudinal study of pregnancy outcome following idiopathic recurrent miscarriage. Human Reproduction 14 2868-2871. (doi:10.1093/humrep/14.11.2868)

Brosens J, Pijnenborg R \& Brosens IA 2002 The myometrial junctional zone spiral arteries in normal and abnormal pregnancies: a review of the literature. American Journal of Obstetrics and Gynecology 187 1416-1423. (doi:10.1067/mob.2002.127305) 
Brosens JJ, Salker MS, Teklenburg G, Nautiyal J, Salter S, Lucas ES, Steel JH, Christian M, Chan YW, Boomsma CM et al. 2014 Uterine selection of human embryos at implantation. Scientific Reports 43894 (doi:10.1038/srep03894)

Burton GJ, Jauniaux E \& Watson AL 1999 Maternal arterial connections to the placental intervillous space during the first trimester of human pregnancy: the Boyd collection revisited. American Journal of Obstetrics and Gynecology 181 718-724. (doi:10.1016/S0002-9378(99)70518-1)

Chan RW, Schwab KE \& Gargett CE 2004 Clonogenicity of human endometrial epithelial and stromal cells. Biology of Reproduction $\mathbf{7 0}$ 1738-1750. (doi:10.1095/biolreprod.103.024109)

Chen G, Bradford WD, Seidel CW \& Li R 2012 Hsp90 stress potentiates rapid cellular adaptation through induction of aneuploidy. Nature $\mathbf{4 8 2}$ 246-250. (doi:10.1038/nature10795)

Cheung TH \& Rando TA 2013 Molecular regulation of stem cell quiescence. Nature Reviews. Molecular Cell Biology 14 329-340. (doi:10.1038/ nrm3591)

Coomarasamy A, Williams H, Truchanowicz E, Seed PT, Small R, Quenby S, Gupta P, Dawood F, Koot YE, Bender Atik R et al. 2015 A randomized trial of progesterone in women with recurrent miscarriages. New England Journal of Medicine 373 2141-2148. (doi:10.1056/NEJMoa1504927)

Duncan AW, Hanlon Newell AE, Bi W, Finegold MJ, Olson SB, Beaudet AL \& Grompe M 2012 Aneuploidy as a mechanism for stress-induced liver adaptation. Journal of Clinical Investigation 122 3307-3315. (doi:10.1172/JCl64026)

Fragouli E, Alfarawati S, Spath K, Jaroudi S, Sarasa J, Enciso M \& Wells D 2013 The origin and impact of embryonic aneuploidy. Human Genetics 132 1001-1013. (doi:10.1007/s00439-013-1309-0)

Francis J, Rai R, Sebire NJ, El-Gaddal S, Fernandes MS, Jindal P, Lokugamage A, Regan L \& Brosens JJ 2006 Impaired expression of endometrial differentiation markers and complement regulatory proteins in patients with recurrent pregnancy loss associated with antiphospholipid syndrome. Molecular Human Reproduction 12 435-442. (doi:10.1093/molehr/gal048)

Gargett CE, Schwab KE \& Deane JA 2016 Endometrial stem/progenitor cells: the first 10 years. Human Reproduction Update 22 137-163.

Gellersen B \& Brosens JJ 2014 Cyclic decidualization of the human endometrium in reproductive health and failure. Endocrine Reviews 35 851-905. (doi:10.1210/er.2014-1045)

Greco E, Minasi MG \& Fiorentino F 2015 Healthy babies after intrauterine transfer of mosaic aneuploid blastocysts. New England Journal of Medicine 373 2089-2090. (doi:10.1056/NEJMc1500421)

Haig D 1993 Genetic conflicts in human pregnancy. Quarterly Review of Biology 68 495-532. (doi:10.1086/418300)

Hoenicke L \& Zender L 2012 Immune surveillance of senescent cells biological significance in cancer- and non-cancer pathologies. Carcinogenesis 33 1123-1126. (doi:10.1093/carcin/bgs124)

Kajihara T, Jones M, Fusi L, Takano M, Feroze-Zaidi F, Pirianov G, Mehmet H, Ishihara O, Higham JM, Lam EW et al. 2006 Differential expression of FOXO1 and FOXO3a confers resistance to oxidative cell death upon endometrial decidualization. Molecular Endocrinology 20 2444-2455. (doi:10.1210/me.2006-0118)

Kaya A, Gerashchenko MV, Seim I, Labarre J, Toledano MB \& Gladyshev VN 2015 Adaptive aneuploidy protects against thiol peroxidase deficiency by increasing respiration via key mitochondrial proteins. PNAS 112 10685-10690. (doi:10.1073/pnas.1505315112)

Klemmt PA, Carver JG, Kennedy SH, Koninckx PR \& Mardon HJ 2006 Stromal cells from endometriotic lesions and endometrium from women with endometriosis have reduced decidualization capacity. Fertility and Sterility 85 564-572. (doi:10.1016/j.fertnstert.2005.08.046)

Kuroda K, Venkatakrishnan R, James S, Sucurovic S, Mulac-Jericevic B, Lucas ES, Takeda S, Shmygol A, Brosens JJ \& Quenby S 2013a Elevated periimplantation uterine natural killer cell density in human endometrium is associated with impaired corticosteroid signaling in decidualizing stromal cells. Journal of Clinical Endocrinology and Metabolism 98 4429-4437. (doi:10.1210/jc.2013-1977)

Kuroda K, Venkatakrishnan R, Salker MS, Lucas ES, Shaheen F, Kuroda M, Blanks A, Christian M, Quenby S \& Brosens JJ 2013b Induction of 11 beta-HSD 1 and activation of distinct mineralocorticoid receptorand glucocorticoid receptor-dependent gene networks in decidualizing human endometrial stromal cells. Molecular Endocrinology 27 192-202. (doi:10.1210/me.2012-1247)
Leitao B, Jones MC, Fusi L, Higham J, Lee Y, Takano M, Goto T, Christian M, Lam EW \& Brosens JJ 2010 Silencing of the JNK pathway maintains progesterone receptor activity in decidualizing human endometrial stromal cells exposed to oxidative stress signals. FASEB Journal $\mathbf{2 4}$ 1541-1551. (doi:10.1096/fj.09-149153)

Leitao BB, Jones MC \& Brosens JJ 2011 The SUMO E3-ligase PIAS1 couples reactive oxygen species-dependent JNK activation to oxidative cell death. FASEB Journal 25 3416-3425. (doi:10.1096/fj.11-186346)

Liu G, Yong MY, Yurieva M, Srinivasan KG, Liu J, Lim JS, Poidinger M, Wright GD, Zolezzi F, Choi H et al. 2015 Gene essentiality is a quantitative property linked to cellular evolvability. Cell 163 1388-1399. (doi:10.1016/j.cell.2015.10.069)

Lucas ES, Dyer NP, Murakami K, Hou Lee Y, Chan YW, Grimaldi G, Muter J, Brighton PJ, Moore JD, Patel G et al. 2016 Loss of endometrial plasticity in recurrent pregnancy loss. Stem Cells 34 346-356. (doi:10.1002/ stem.2222)

Macklon NS \& Brosens JJ 2014 The human endometrium as a sensor of embryo quality. Biology of Reproduction 91 98. (doi:10.1095/ biolreprod.114.122846)

Mansouri-Attia N, Sandra O, Aubert J, Degrelle S, Everts RE, GiraudDelville C, Heyman Y, Galio L, Hue I, Yang X et al. 2009 Endometrium as an early sensor of in vitro embryo manipulation technologies. PNAS 106 5687-5692. (doi:10.1073/pnas.0812722106)

Masuda H, Anwar SS, Buhring HJ, Rao JR \& Gargett CE 2012 A novel marker of human endometrial mesenchymal stem-like cells. Cell Transplantation 21 2201-2214. (doi:10.3727/096368911X637362)

Millet C, Ausiannikava D, Le Bihan T, Granneman S \& Makovets S 2015 Cell populations can use aneuploidy to survive telomerase insufficiency. Nature Communications 6 8664. (doi:10.1038/ncomms9664)

Murakami K, Bhandari H, Lucas ES, Takeda S, Gargett CE, Quenby S, Brosens JJ \& Tan BK 2013 Deficiency in clonogenic endometrial mesenchymal stem cells in obese women with reproductive failure - a pilot study. PLOS ONE 8 e82582. (doi:10.1371/journal.pone.0082582)

Murakami K, Lee YH, Lucas ES, Chan YW, Durairaj RP, Takeda S, Moore JD, Tan BK, Quenby S, Chan JK et al. 2014 Decidualization induces a secretome switch in perivascular niche cells of the human endometrium. Endocrinology 155 4542-4553. (doi:10.1210/en.2014-1370)

Muter J, Lucas ES, Chan YW, Brighton PJ, Moore JD, Lacey L, Quenby S, Lam EW \& Brosens JJ 2015 The clock protein period 2 synchronizes mitotic expansion and decidual transformation of human endometrial stromal cells. FASEB Journal 29 1603-1614. (doi:10.1096/fj.14267195)

Mutlu L, Hufnagel D \& Taylor HS 2015 The endometrium as a source of mesenchymal stem cells for regenerative medicine. Biology of Reproduction 92 138. (doi:10.1095/biolreprod.114.126771)

Nancy P, Tagliani E, Tay CS, Asp P, Levy DE \& Erlebacher A 2012 Chemokine gene silencing in decidual stromal cells limits $T$ cell access to the maternal-fetal interface. Science 336 1317-1321. (doi:10.1126/ science.1220030)

Ogasawara M, Aoki K, Okada S \& Suzumori K 2000 Embryonic karyotype of abortuses in relation to the number of previous miscarriages. Fertility and Sterility 73 300-304. (doi:10.1016/S0015-0282(99)00495-1)

Orlando J \& Coulam C 2014 is superfertility associated with recurrent pregnancy loss? American Journal of Reproductive Immunology $\mathbf{7 2}$ 549-554. (doi:10.1111/aji.2014.72.issue-6)

Pasquier E, De Saint Martin L, Bohec C, Chauleur C, Bretelle F, Marhic G, Le Gal G, Debarge V, Lecomte F, Denoual-Ziad C et al. 2015 Enoxaparin for prevention of unexplained recurrent miscarriage: a multicenter randomized double-blind placebo-controlled trial. Blood $\mathbf{1 2 5}$ 2200-2205. (doi:10.1182/blood-2014-11-610857)

Piltonen TT, Chen J, Erikson DW, Spitzer TL, Barragan F, Rabban JT, Huddleston H, Irwin JC \& Giudice LC 2013 Mesenchymal stem/ progenitors and other endometrial cell types from women with polycystic ovary syndrome (PCOS) display inflammatory and oncogenic potential. Journal of Clinical Endocrinology and Metabolism $\mathbf{9 8}$ 3765-3775. (doi:10.1210/jc.2013-1923)

Piltonen TT, Chen JC, Khatun M, Kangasniemi M, Liakka A, Spitzer T, Tran N, Huddleston H, Irwin JC \& Giudice LC 2015 Endometrial stromal fibroblasts from women with polycystic ovary syndrome have impaired progesterone-mediated decidualization, aberrant cytokine profiles and promote enhanced immune cell migration in vitro. Human Reproduction 30 1203-1215. (doi:10.1093/humrep/dev055) 
Practice Committee of the American Society for Reproductive Medicine 2012 Evaluation and treatment of recurrent pregnancy loss: a committee opinion. Fertility and Sterility 98 1103-1111. (doi:10.1016/j. fertnstert.2012.06.048)

Rai R \& Regan L 2006 Recurrent miscarriage. Lancet 368 601-611. (doi:10.1016/S0140-6736(06)69204-0)

Ramsahoye BH, Biniszkiewicz D, Lyko F, Clark V, Bird AP \& Jaenisch R 2000 Non-CpG methylation is prevalent in embryonic stem cells and may be mediated by DNA methyltransferase 3a. PNAS 97 5237-5242. (doi:10.1073/pnas.97.10.5237)

Ramsey EM, Houston ML \& Harris JW 1976 Interactions of the trophoblast and maternal tissues in three closely related primate species. American Journal of Obstetrics and Gynecology 124 647-652. (doi:10.1016/00029378(76)90068-5)

Refuerzo JS 2012 Impact of multiple births on late and moderate prematurity. Seminars in Fetal and Neonatal Medicine 17 143-145. (doi:10.1016/j.siny.2012.01.012)

Salker M, Teklenburg G, Molokhia M, Lavery S, Trew G, Aojanepong T, Mardon HJ, Lokugamage AU, Rai R, Landles C et al. 2010 Natural selection of human embryos: impaired decidualization of the endometrium disables embryo-maternal interactions and causes recurrent pregnant loss. PLOS ONE 5 e10287. (doi:10.1371/journal. pone.0010287)

Salker MS, Christian M, Steel JH, Nautiyal J, Lavery S, Trew G, Webster Z, Al-Sabbagh M, Puchchakayala G, Foller M et al. 2011 Deregulation of the serum- and glucocorticoid-inducible kinase SGK1 in the endometrium causes reproductive failure. Nature Medicine $\mathbf{1 7}$ 1509-1513. (doi:10.1038/nm.2498)

Salker MS, Nautiyal J, Steel JH, Webster Z, Sucurovic S, Nicou M, Singh Y, Lucas ES, Murakami K, Chan YW et al. 2012 Disordered IL-33/ST2 activation in decidualizing stromal cells prolongs uterine receptivity in women with recurrent pregnancy loss. PLOS ONE 7 e52252. (doi:10.1371/journal.pone.0052252)

Saravelos SH \& Regan L 2014 Unexplained recurrent pregnancy loss. Obstetrics and Gynecology Clinics of North America 41 157-166. (doi:10.1016/j.ogc.2013.10.008)

Shirane K, Toh H, Kobayashi H, Miura F, Chiba H, Ito T, Kono T \& Sasaki H 2013 Mouse oocyte methylomes at base resolution reveal genome-wide accumulation of non-CpG methylation and role of DNA methyltransferases. PLoS Genetics 9 e1003439. (doi:10.1371/journal. pgen.1003439)

Tabibzadeh S, Mason JM, Shea W, Cai Y, Murray MJ \& Lessey B 2000 Dysregulated expression of ebaf, a novel molecular defect in the endometria of patients with infertility. Journal of Clinical Endocrinology and Metabolism 85 2526-2536.(doi:10.1210/jc.85.7.2526)

Tang M, Taylor HS \& Tabibzadeh S 2005 In vivo gene transfer of lefty leads to implantation failure in mice. Human Reproduction 20 1772-1778. (doi:10.1093/humrep/deh849)
Taylor J 2016 Evolutionary biology takes a hard look at IVF and human conception. Evolution and Medicine Review. (https://evmedreview.com/ evolutionary-biology-takes-a-hard-look-at-ivf-and-human-conception/)

Taylor TH, Gitlin SA, Patrick JL, Crain JL, Wilson JM \& Griffin DK 2014 The origin, mechanisms, incidence and clinical consequences of chromosomal mosaicism in humans. Human Reproduction Update $\mathbf{2 0}$ 571-581. (doi:10.1093/humupd/dmu016)

Teklenburg G, Salker M, Heijnen C, Macklon NS \& Brosens JJ 2010 The molecular basis of recurrent pregnancy loss: impaired natural embryo selection. Molecular Human Reproduction 16 886-895. (doi:10.1093/ molehr/gaq079)

Ulrich D, Tan KS, Deane J, Schwab K, Cheong A, Rosamilia A \& Gargett CE 2014 Mesenchymal stem/stromal cells in post-menopausal endometrium. Human Reproduction 29 1895-1905. (doi:10.1093/humrep/deu159)

Vanneste E, Voet T, Le Caignec C, Ampe M, Konings P, Melotte C, Debrock S, Amyere M, Vikkula M, Schuit F et al. 2009 Chromosome instability is common in human cleavage-stage embryos. Nature Medicine 15 577-583. (doi:10.1038/nm.1924)

Vlaanderen W 2014 Recurrent miscarriage: guidelines could be improved. Human Reproduction 29 1344-1345. (doi:10.1093/humrep/deu061)

Wang H \& Dey SK 2006 Roadmap to embryo implantation: clues from mouse models. Nature Reviews Genetics 7 185-199. (doi:10.1038/ nrg1808)

Wang Q, Ding G \& Xu X 2016 Immunomodulatory functions of mesenchymal stem cells and possible mechanisms. Histology and Histopathology 31 949-959. (doi:10.14670/HH-11-750)

Wong SP, Rowley JE, Redpath AN, Tilman JD, Fellous TG \& Johnson JR 2015 Pericytes, mesenchymal stem cells and their contributions to tissue repair. Pharmacology \& Therapeutics 151 107-120. (doi:10.1016/j. pharmthera.2015.03.006)

Yoshino O, Osuga Y, Hirota Y, Koga K, Hirata T, Yano T, Ayabe T, Tsutsumi O \& Taketani Y 2003 Endometrial stromal cells undergoing decidualization down-regulate their properties to produce proinflammatory cytokines in response to interleukin-1 beta via reduced p38 mitogen-activated protein kinase phosphorylation. Journal of Clinical Endocrinology and Metabolism 88 2236-2241. (doi:10.1210/jc.2002-021788)

Ziller MJ, Muller F, Liao J, Zhang Y, Gu H, Bock C, Boyle P, Epstein CB, Bernstein BE, Lengauer T et al. 2011 Genomic distribution and intersample variation of non-CpG methylation across human cell types. PLoS Genetics 7 e1002389. (doi:10.1371/journal.pgen.1002389)

Received 7 June 2016

First decision 6 July 2016

Revised manuscript received 6 July 2016

Accepted 18 July 2016 